\title{
Photo-Probe Study of Siloxane Polymers II. Local Structure and Dynamics of MQ-Type Silicone Resin Probed by Fluorescence Depolarization of Perylene
}

\author{
Kimihiko YoshII, ${ }^{\dagger}$ Shinjiro MachIDA, Kazuyuki HoRIE, ${ }^{\dagger}$ \\ and Maki ITOH* \\ Department of Chemistry and Biotechnology, Graduate School of Engineering, \\ The University of Tokyo, 7-3-1 Hongo, Bunkyo-ku, Tokyo 113-8656, Japan \\ * Dow Corning Asia Ltd., Research Center, 603 Kishi, Yamakita, \\ Kanagawa 258-0112, Japan
}

(Received May 13, 1999)

\begin{abstract}
We investigated the local structure and dynamics of three-dimensionally crosslinked polysiloxane, an MQ-type silicone resin, using fluorescence depolarization of perylene molecularly dispersed in the resin. Rotational diffusion coefficient, $D_{\mathrm{r}}$, of perylene was determined in uncured and cured MQ resins and in PMMA over a temperature range of $90-300 \mathrm{~K} . D_{\mathrm{r}}$ in the uncured MQ resin (a mixture of prepolymers), i.e., an assembly of crosslinked nanometer-scale particles, is $5-10 \times 10^{8} \mathrm{~s}^{-1}$ at room temperature and shows continuous drastic decrease with decreasing temperature to $10^{6} \mathrm{~s}^{-1}$ at $90 \mathrm{~K}$. $D_{\mathrm{r}}$ in the cured MQ resins is $10^{7} \mathrm{~s}^{-1}$ and almost independent of temperature. $D_{\mathrm{r}}$ in the cured MQ resins is thus larger than that in the uncured prepolymer at $90 \mathrm{~K}$. A possible explanation is as follows. The thermal fluctuation of nanoparticles caused by the $\mathrm{Si}-\mathrm{O}-\mathrm{Si}$ chain flexibility becomes weak with decreasing temperature in the uncured prepolymer, and change in packing and dense aggregation of the nanoparticles around perylene molecules cause the gradual increase in restriction against rotation of perylene from room temperature to $90 \mathrm{~K}$. In the cured MQ resins, hydrosilylation curing reaction would fix the spatial position of the nanoparticles and retain the local space around perylene even at low temperatures. The results of fluorescence depolarization are compared with those of photoisomerization of azobenzene in the MQ resin in our previous study.

KEY WORDS Polysiloxane / Fluorescence Depolarization / Silicone Resin / Rotational Diffusion Coefficicnt / Perylene / Photoisomerization / Azobenzene /
\end{abstract}

Silicone resins having three-dimensional crosslinked structures are widely used as coatings and additives. ${ }^{1}$ Local structure, e.g., local free volume, local viscosity, or combination of each constitutional unit, is a key to understand the relationships between chemical process and macroscopic physical properties for silicone resins. Many studies have been carried out on crosslink formation during the hydrolysis and condensation of tetraethyl orthosilicate (TEOS) or tetramethyl orthosilicate (TMOS) either theoretically ${ }^{2,3}$ or experimentally with ${ }^{29} \mathrm{Si} \mathrm{NMR}^{4-7}$ and GPC. ${ }^{8}$ Macroscopic properties of siloxane polymers have been reported. ${ }^{9}$ Few reports have been published on microscopic structural characterization of silicone resins, for which the establishment of the methodology is essential.

The previous study ${ }^{10}$ used trans-to-cis photoisomerization of azobenzene as a probe over the temperature range of $4-300 \mathrm{~K}$ to investigate local free volume and thermal fluctuation of an MQ-type silicone resin consisting of $\mathrm{M}\left(\mathrm{R}_{3} \mathrm{SiO}_{1 / 2}\right)$ units and $\mathrm{Q}\left(\mathrm{SiO}_{4 / 2}\right)$ units in comparison with other matrices including linear polysiloxanes and a carbon-based linear polymer, poly(methyl methacrylate) (PMMA). We believe the uncured MQ resin or the prepolymer of the MQ resin to be an assembly of crosslinked nanometer-scale particles and curing reaction links the nanoparticles. Local space outside the nanoparticles not inside the particles was probed by photoisomerization of azobenzene. Trans-to-cis photoisomerization was evaluated mainly from the viewpoint of the final cis fraction after sufficient UV light irradiation to the photoequilibrium state. Temperature dependence of the final cis fraction suggested the following two points: First, the intrinsic size of local free volume evaluated from the final cis fraction at $4 \mathrm{~K}$ in the siloxane polymers including the uncured and cured MQ resins and linear polysiloxanes is smaller than PMMA. But the size of the local free volume in siloxane polymers including the effects of thermal relaxation of the matrices increases drastically between $4 \mathrm{~K}$ and $20 \mathrm{~K}$, and thermal fluctuation of the local free volume in the siloxane polymers is much larger than that of PMMA. This is consistent with the general recognition that siloxane polymers are soft material having large free volume near room temperature. The fluctuation can arise from relaxation of siloxane $\mathrm{Si}-\mathrm{O}-\mathrm{Si}$ chain in the uncured prepolymer and linear polysiloxanes. Secondly, the aggregation of prepolymer nanoparticles at low temperatures prevents azobenzene from photoisomerizing and the curing reaction between the nanoparticles disturbs the aggregation resulting in enough space for azobenzene to photoisomerize at $4 \mathrm{~K}$.

Positron annihilation on the cured MQ resin ${ }^{11}$ indicated that the average diameter of the local free volume inside the nanoparticles was $0.8 \mathrm{~nm}$ at room temperature and $0.6 \mathrm{~nm}$ at $50 \mathrm{~K}$. The results of positron annihilation evaluating inside the MQ resin nanoparticles complement those of photoisomerization of azobenzene evaluating local free volume outside the particles.

In the present study, local viscosity and size of local space in the uncured MQ resin prepolymers and cured MQ resins were evaluated by fluorescence depolarization of perylene. Steady-state and time-resolved fluorescence 
have been widely used for high resolution to evaluate microstructure and molecular motion. ${ }^{12}$ Fluorescence depolarization has been used for investigating the dynamics and orientation in polymer solution and polymer solids. When a probe chromophore is attached to a polymer chain, information on chain conformation and segment mobility of the chain ${ }^{13-19}$ is obtained. In contrast, Brownian motion of doped dye molecules is affected by local viscosity and local free volume of matrices. ${ }^{20-23}$ Rotational diffusion coefficients, $D_{\mathrm{r}}$, of doped perylene in the uncured and cured MQ resins and in PMMA are derived from fluorescence anisotropy ratio and fluorescence lifetime in the temperature range of $90-300 \mathrm{~K}$. At room temperature perylene molecule rotates freely in the uncured prepolymers while in the cured MQ resins the mobility of perylene is restricted. $D_{\mathrm{r}}$ in the uncured prepolymers shows continuous rapid decrease with decrease in temperature, while in the cured resins it is almost independent of temperature. $D_{\mathrm{r}}$ in the uncured prepolymer is thus smaller than that in the cured MQ resin at $90 \mathrm{~K}$, which is contrary to the results at room temperature. These results suggest that uncured prepolymer nanoparticles prevent perylene from rotating by being packed locally around it at $90 \mathrm{~K}$, while the curing reaction between the nanoparticles retains enough space for perylene to rotate at $90 \mathrm{~K}$. The present fluorescence depolarization proves the continuous aggregation of the nanoparticles in the uncured prepolymer in the temperature range from 300 to $90 \mathrm{~K}$ for the first time, which could not be shown in the azobenzene study.

\section{EXPERIMENTAL}

\section{Materials}

TEOS (Wako), TMOS, tetramethyldivinyldisiloxane, and tetramethyldisiloxane (Shin-Etsu Silicone) were used as received. PMMA (Wako, $M_{w}=1.04 \times 10^{5}$ ) was used after reprecipitation in methanol. Perylene (Tokyo Kasei) was used as received.

\section{Prepolymer (Uncured MQ Resin) Preparation and Characterization}

A vinyl prepolymer consists of vinyldimethylsiloxy $\left(\left(\mathrm{CH}_{2}=\mathrm{CH}\right)\left(\mathrm{CH}_{3}\right)_{2} \mathrm{SiO}_{1 / 2}, \mathrm{M}^{\mathrm{Vi}}\right)$ units and $\mathrm{Q}\left(\mathrm{SiO}_{4 / 2}\right)$ units, while an $\mathrm{SiH}$ prepolymer consists of hydridodimethylsiloxy $\left((\mathrm{H})\left(\mathrm{CH}_{3}\right)_{2} \mathrm{SiO}_{1 / 2}, \mathrm{M}^{\mathrm{H}}\right)$ units and $\mathrm{Q}$ units. Vinyl prepolymers were prepared from TEOS and tetramethyldivinyldisiloxane by hydrolysis and condensation, while $\mathrm{Si}-\mathrm{H}$ prepolymers were from TMOS and tetramethyldisiloxane. Each uncured prepolymer is colorless viscous liquid at room temperature. The preparation of each prepolymer is described in our previous paper. ${ }^{10}$ Gel permeation chromatography (GPC) curves were obtained by a Tosoh HLC-8020 gel permeation chromatograph equipped with a refractive index detector. The columns used were TSKgel $\mathrm{GMH}_{\mathrm{XL}}-\mathrm{L}+\mathrm{G} 1000 \mathrm{H}_{\mathrm{XL}}$ with toluene as an eluent. ${ }^{29} \mathrm{Si}$ NMR spectra were recorded on a Bruker ACP-300 spectrometer in $\mathrm{CDCl}_{3}$. Chromium acetylacetonate was used as a relaxation agent at $0.02 \mathrm{M}$ and a gated decoupling in which protons were irradiated only during the acquisition of FID was used with the pulse width of
Table I. $\mathrm{M} / \mathrm{Q}$ feed ratio in moles, $\mathrm{M} / \mathrm{Q}$ ratio, weight-average molecular weight, and viscosity of each uncured prepolymer for preparation of prepolymer mixtures ${ }^{a}$

\begin{tabular}{lcccc}
\hline Prepolymer & $\begin{array}{c}\mathrm{M} / \mathrm{Q} \\
\text { feed ratio }\end{array}$ & $\begin{array}{c}\mathrm{M} / \mathrm{Q} \\
\text { ratio }^{\mathrm{b}}\end{array}$ & $M_{w}{ }^{\mathrm{c}}$ & Viscosity $/ \mathrm{cP}$ \\
\cline { 1 - 1 } Vinyl prepolymer 1 & 1.5 & 1.7 & 1500 & 2780 \\
Vinyl prepolymer 2 & 2 & 1.9 & 1200 & 160 \\
SiH prepolymer 1 & 1 & 1.2 & 2000 & 520 \\
SiH prepolymer 2 & 2 & 1.8 & 1000 & 40
\end{tabular}

${ }^{a}$ Uncured prepolymer mixture 1 was prepared from vinyl prepolymer 1 and $\mathrm{SiH}$ prepolymer 1 . Uncured prepolymer mixture 2 was prepared from vinyl prepolymer 2 and $\mathrm{SiH}$ prepolymer 2 . ${ }^{\mathrm{b}}$ Obtained by ${ }^{29} \mathrm{Si}$ NMR. ${ }^{c}$ Determined with GPC based on polystyrene standards. ${ }^{\mathrm{d}}$ Measured at $24^{\circ} \mathrm{C}$ with density as $1.0 \mathrm{~g} \mathrm{~cm}^{-3}$.

$5.4 \mu \mathrm{s}$ (pulse angle of $45^{\circ}$ ) and the pulse delay of $10 \mathrm{~s}$. The viscosity, $\eta$, of each prepolymer at $24^{\circ} \mathrm{C}$ was measured with an Ubbelohde-type viscometer. Density was assumed to be $1.0 \mathrm{~g} \mathrm{~cm}^{-3}$.

By changing the feed $M / Q$ ratio in moles, vinyl prepolymers 1 and 2 and $\mathrm{SiH}$ prepolymers 1 and 2 were prepared. The feed $\mathrm{M} / \mathrm{Q}$ ratio in moles, GPC weightaverage molecular weight, $M_{w}$, relative to polystyrene standards, the $\mathrm{M} / \mathrm{Q}$ ratio determined by ${ }^{29} \mathrm{Si} \mathrm{NMR}$, and the $\eta$ for each prepolymer at $24^{\circ} \mathrm{C}$ are shown in Table I. Uncured prepolymer mixture 1 was prepared by mixing vinyl prepolymer 1 and $\mathrm{SiH}$ prepolymer 1 when the molar concentration of the vinyl group was equivalent to that of the $\mathrm{Si}-\mathrm{H}$ group. Uncured prepolymer mixture 2 was prepared from vinyl prepolymer 2 and $\mathrm{SiH}$ prepolymer 2 in the same way.

\section{Sample Preparation}

The uncured prepolymer mixture containing molecularly dispersed perylene $\left(4 \times 10^{-5} \mathrm{M}\right)$ but without catalyst was placed in a $1-\mathrm{mm}$ thick quartz cell for fluorescence measurement. The cured MQ resin films containing molecularly dispersed perylene were prepared as follows. The prepolymers $(6.5 \mathrm{~g}$ of the vinyl prepolymer 1 and $6.1 \mathrm{~g}$ of the $\mathrm{Si}-\mathrm{H}$ prepolymer 1) without solvent were mixed with a toluene solution of platinum-divinyltetramethyldisiloxane complex $(15 \mu \mathrm{L}, 2.2 \mathrm{wt} \%)$ as crosslinking catalyst $(20-30 \mathrm{ppm}$ of total weight of the mixture) and dichloromethane solution of perylene $(0.4 \mathrm{~mL}, 1.2 \mathrm{mM})$ at room temperature. The mixture was stirred vigorously before being dried at room temperature for $3 \mathrm{~h}$ to eliminate solvents, followed by casting on a glass plate. Sample films $(400-700 \mu \mathrm{m}$ in thickness) were cured by stepwise heating for hydrosilylation reaction. After heating at $60^{\circ} \mathrm{C}$ for $2 \mathrm{~h}$ some sample films were taken out (cured MQ 60). The other films were further cured at $100^{\circ} \mathrm{C}$ for $1 \mathrm{~h}$ and then at $120^{\circ} \mathrm{C}$ for $2 \mathrm{~h}$ and finally at $150^{\circ} \mathrm{C}$ for $1 \mathrm{~h}$, giving cured MQ 100, cured MQ 120, and cured MQ 150 taken out after each heating step, respectively. The number for each cured resin sample shows the final curing temperature. Four cured MQ resins with different degrees of cure were prepared. The degree of cure was determined by change in the infrared absorption using an IR spectrophotometer (Jasco IR-700). The decrease in IR absorption bands at $2138 \mathrm{~cm}^{-1}\left(\mathrm{Si}-\mathrm{H}\right.$ stretching) and at $1597 \mathrm{~cm}^{-1}(\mathrm{C}=\mathrm{C}$ stretching) was monitored during cure using the absorption at $2964 \mathrm{~cm}^{-1}$ (C-H stretching of methyl groups) 
Table II. Degree of cure for each cured MQ resin Curing time and temperature is specified in the experimental section

\begin{tabular}{cc} 
Sample & Degree of cure $(\%)^{a}$ \\
\hline Cured MQ 60 & 11 \\
Cured MQ 100 & 16 \\
Cured MQ 120 & 31 \\
Cured MQ 150 & 47
\end{tabular}

${ }^{a}$ Determined from change in IR.

as an internal standard. The degree of cure of each cured MQ resin is shown in Table II. PMMA films were prepared by the solvent-cast method from a $10 \mathrm{wt} \%$ dichloromethane solution containing perylene. PMMA films after being dried at room temperature were heated under vacuum at $100^{\circ} \mathrm{C}$ for $12 \mathrm{~h}$ to eliminate the residual solvent.

\section{Fluorescence Measurements}

Steady-state fluorescence anisotropy ratio, $r$, was measured with a Hitachi 650 fluorescence spectrometer equipped with polarizers in the right-angle configuration. The value of $r$ was calculated by using eq 1 ,

$$
r=\frac{I_{\mathrm{vv}}-G I_{\mathrm{vH}}}{I_{\mathrm{vV}}+2 G I_{\mathrm{vH}}}
$$

where $G=I_{\mathrm{HV}} / I_{\mathrm{HH}}$ is an instrumental correction factor. In eq $1, I_{\mathrm{VV}}, I_{\mathrm{VH}}, I_{\mathrm{HV}}$, and $I_{\mathrm{HH}}$ are emission intensity, where two subscripts indicate the vertical or horizontal orientation of the excitation (first subscript) and emission (second subscript) polarizers, respectively. Sample films containing perylene set in a cryostat (Oxford DN-1754) were excited at $435 \mathrm{~nm}$ and $r$ was averaged for the $463-473 \mathrm{~nm}$ emission range.

Fluorescence decay was measured by single-photon counting for determination of fluorescence lifetime, $\tau$. Perylene was excited at $337 \mathrm{~nm}$ from an $\mathrm{N}_{2}$ laser (Laser Photonics LN120) and emission light passing through a glass fiber was monitored with a streak camera (Hamamatsu C4334) attached with a monochromator. FWHM of the instrument response was $c a$. $1.6 \mathrm{~ns}$. To eliminate scattered exciting light, a color filter (UV38) was used. Decay curves were analyzed as single exponential decay using Photolumi ver. 2.47 program (Hamamatsu Photonics).

\section{RESULTS AND DISCUSSION}

\section{Rotational Diffusion Coefficients of Perylene in $M Q-T y p e$ Silicone Resins}

The prepolymers of MQ resins are proposed to be an assembly of crosslinked nanometer-scale particles, where three-dimensionally combined $Q$ units are capped by $\mathbf{M}$ units at the surface. The proposed microstructure of each $M$ and $Q$ unit combination in the $M Q$ resins based on $M / Q$ molar ratio with the location of perylene molecules is schematically illustrated in Figure 1. The amount of added perylene, ratio of one perylene to 25000 nanoparticles, is much smaller than that illustrated in Figure 1. Micrographs obtained in the transmission electron microscope (TEM) observation ${ }^{10}$ and the results of molecular modeling ${ }^{24}$ are consistent with the

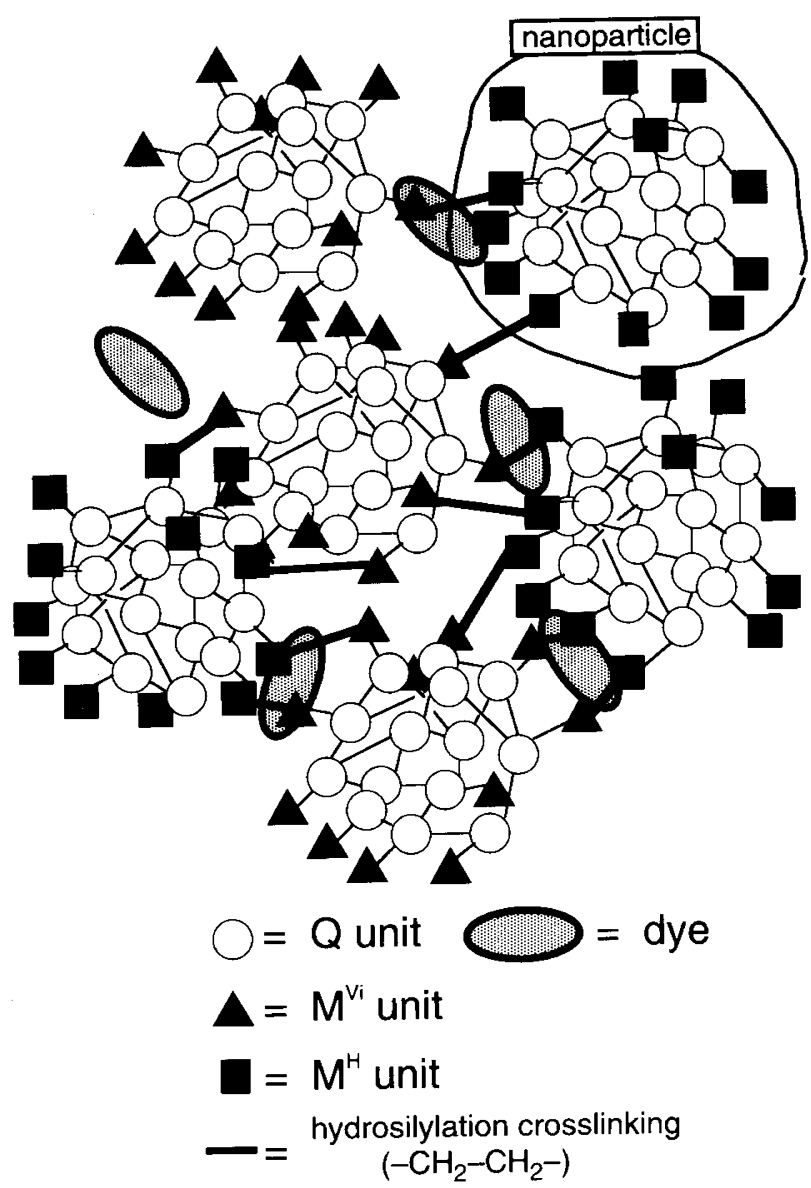

Figure 1. Schematic illustration of $M Q$ resin and doped dye (perylene) molecules

picture in Figure 1.

By fluorescence depolarization, rotation of a probe dye molecule within the lifetime of the excited state can be detected and found the local space and local chain motion in the matrices. Fluorescence anisotropy ratio, $r$, in uncured prepolymer mixtures and cured MQ resins is shown in Figures 2 and 3, respectively. $r$ is very small $(0.011-0.024)$ in the uncured prepolymer mixtures at $300 \mathrm{~K}$, but still ten times larger than $r$ measured in $1 \times 10^{-5} \mathrm{M}$ ethanol solution (0.0018). $r$ rapidly increases with decreasing temperature to $90 \mathrm{~K}$ in the uncured prepolymer mixtures up to 0.3 which is near to the limiting value, $r_{0}$, of fluorescence anisotropy ratio observed in the absence of rotational diffusion and energy transfer. $r$ increases markedly with the degree of cure for cured MQ resins at room temperature, but does not increase so much with decrease in temperature in cured MQ resins and PMMA. Measured fluorescence lifetime, $\tau$, shown in Figure 4 was almost independent of temperature in all matrices with values of $6 \pm 1 \mathrm{~ns}$.

Rotational diffusion coefficient, $D_{\mathrm{r}}$, of perylene was calculated from $r$ and $\tau$ using Perrin-Weber equation given by eq 2 on the Debye-Stokes-Einstein condition ${ }^{25}$ that perylene molecule is regarded as a hard sphere.

$$
\frac{r_{0}}{r}=1+6 D_{\mathrm{r}} \tau
$$

Various values of $r_{0}$ have been reported for perylene in the range of $0.31-0.37 .{ }^{26-30}$ Among them, $0.34^{26}$ was employed. We at first evaluated $D_{\mathrm{r}}$ of perylene in ethanol 


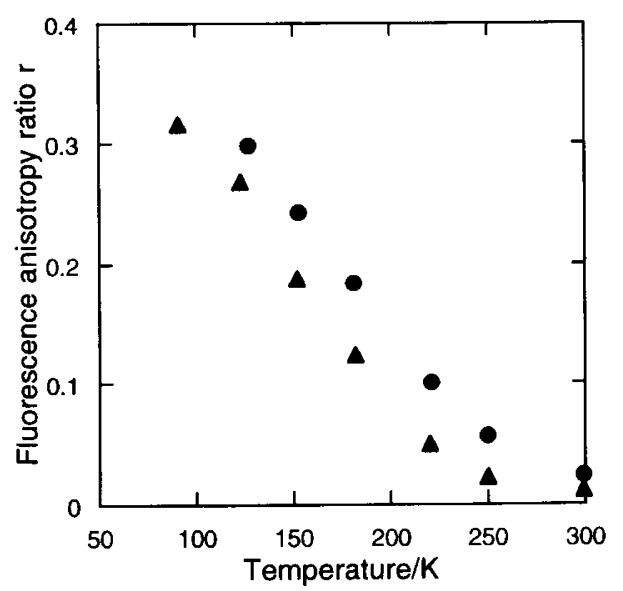

Figure 2. Temperature dependence of the fluorescence anisotropy ratio, $r$, of perylene in uncured prepolymer mixtures $1(\bullet)$ and uncured prepolymer mixture $2(\boldsymbol{\Delta})$.

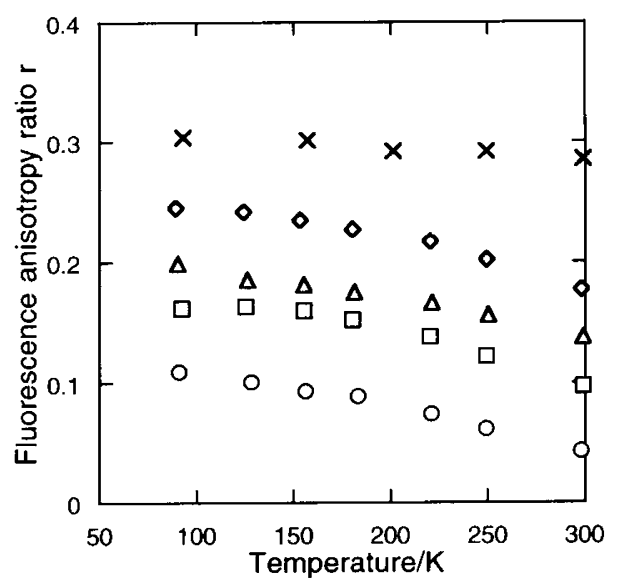

Figure 3. Temperature dependence of the fluorescence anisotropy ratio, $r$, of perylene in cured MQ resins and PMMA: $(O)$ cured MQ $60 ;(\square)$ cured MQ 100; $(\triangle)$ cured MQ $120 ;(\diamond)$ cured MQ 150; $(\times)$ PMMA.

solution. Measured $D_{\mathrm{r}}$ in ethanol solution is $6-8 \times 10^{9}$ $\mathrm{s}^{-1}$ at room temperature, which is in agreement with the reported value $\left((1 \pm 0.3) \times 10^{10} \mathrm{~s}^{-1}\right) .^{27,31}$

$D_{\mathrm{r}}$ against the degree of cure in the uncured and cured MQ resins at room temperature are shown in Figure 5. Figure 5 suggests that the local space is divided finely with increase in cured links and hence the rotation of perylene existing between the nanoparticles becomes much restricted.

$D_{\mathrm{r}}$ in the uncured prepolymer mixture 1 and 2, viscous liquids, are $5 \times 10^{8} \mathrm{~s}^{-1}$ and $10 \times 10^{8} \mathrm{~s}^{-1}$ at room temperature. $D_{\mathrm{r}}$ in the uncured prepolymers are much smaller than those in $n$-pentane $\left(2 \times 10^{10} \mathrm{~s}^{-1}\right)$, and $n$-hexane $\left(1 \times 10^{10} \mathrm{~s}^{-1}\right)$ calculated from reorientation time in these solvents reported by Jiang, ${ }^{32}$ and even smaller than $D_{\mathrm{r}}\left(3 \times 10^{9} \mathrm{~s}^{-1}\right)$ in $n-\mathrm{C}_{16} \mathrm{H}_{34}$ in their experiments. In glycerol, anisotropy decay of perylene was reported to be double exponential and the fast component of the rotational diffusion coefficient was $3.7 \times 10^{7} \mathrm{~s}^{-1}$ at $20^{\circ} \mathrm{C}^{26}$ Viscosity, $\eta$, is about $1000 \mathrm{cP}$ for uncured prepolymer mixture 1 and about $100 \mathrm{cP}$ for uncured prepolymer mixture 2 at $24^{\circ} \mathrm{C}$ shown in Table I. At $25^{\circ} \mathrm{C} \eta$ is reported ${ }^{33} 1.07 \mathrm{cP}$ for ethanol, $3.03 \mathrm{cP}$ for $n-\mathrm{C}_{16} \mathrm{H}_{34}$, and $934 \mathrm{cP}$ for glycerol. Hence, $D_{\mathrm{r}}$ in the

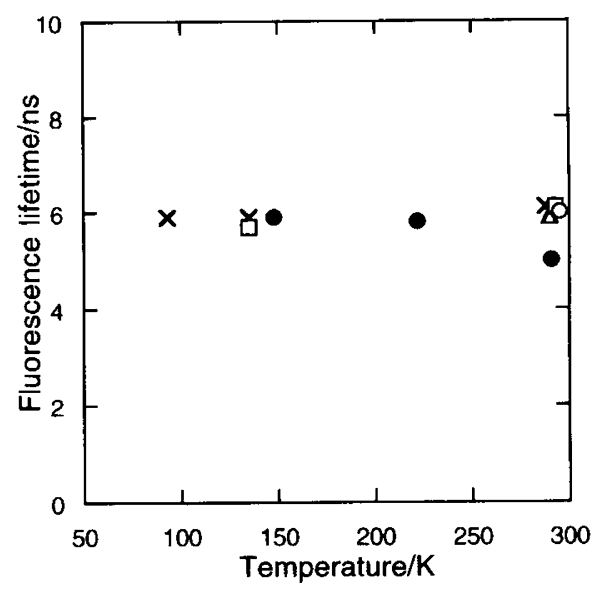

Figure 4. Fluorescence lifetime of perylene in each matrix: (O) uncured prepolymer mixture $1 ;(O)$ cured MQ 60; $(\square)$ cured MQ 100; $(\triangle)$ cured MQ 120; $(\times)$ PMMA.

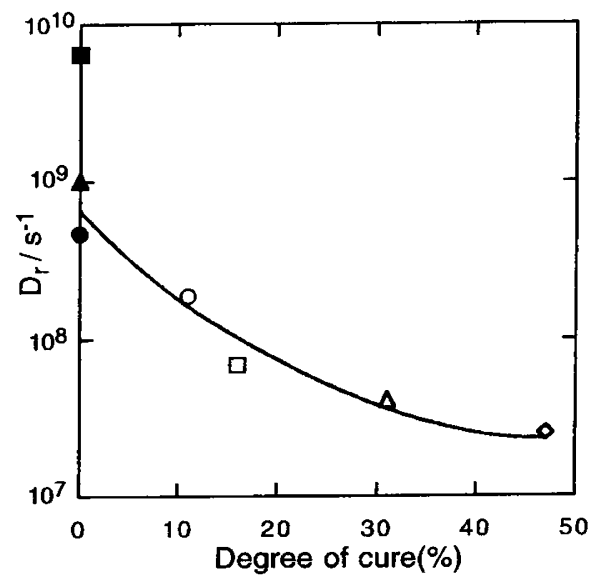

Figure 5. Rotational diffusion coefficient, $D_{r}$, of perylene at room temperature in ethanol solution and uncured and cured MQ resins against degree of cure: $(\boldsymbol{\square})$ ethanol; $(\boldsymbol{O})$ uncured prepolymer mixture 1; (A) uncured prepolymer mixture 2; $(\bigcirc)$ cured MQ 60; $(\square)$ cured MQ $100 ;(\triangle)$ cured MQ $120 ;(\diamond)$ cured MQ 150.

uncured prepolymer mixtures are not proportional to $1 / \eta$ comparing with these organic solvents. This can be explained as follows: First, the size of the prepolymer nanometer-scale molecule is larger than that of the solute perylene molecule (longer axis is $1 \mathrm{~nm}$ ). In such case $D_{\mathrm{r}}$ does not reflect the bulk viscosity of the medium, and is not proportional to $1 / \eta$ because the surroundings cannot be regarded as a continuous medium. Secondly, some prepolymer molecules in the system would not have a simple shape of a particle but the structure of a linked particle. For MQ resins prepared from sodium silicate, ${ }^{29} \mathrm{Si}$ NMR, high resolution TEM, and molecular modeling data were reported which propose the resin structure to be interconnected Q20 polyhedral building blocks. $^{24}$ This is consistent with our GPC pattern consisting of several dispersed peaks. Bulk viscosity for the prepolymers shows a large value for the presence of such linked particles, and thus does not reflect the microviscosity around perylene molecules.

Figure 6 shows temperature dependence of $D_{\mathrm{r}}$ of perylene in uncured and cured MQ resins as well as in PMMA. With decreasing temperature, $D_{\mathrm{r}}$ in the uncured prepolymer mixtures shows continuous drastic decrease. 


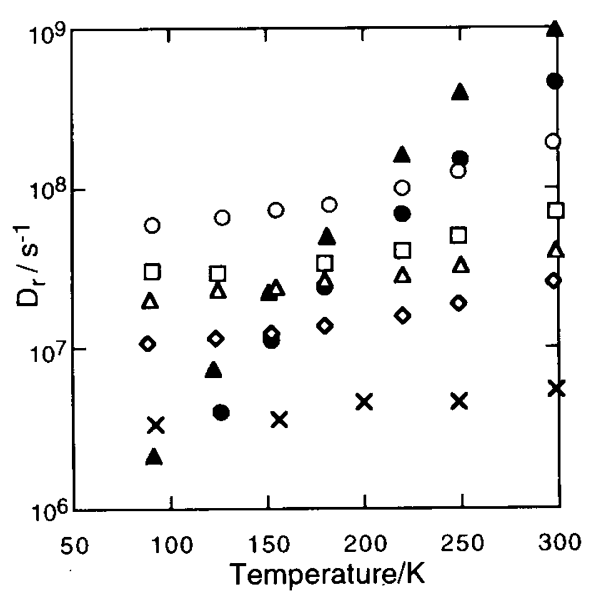

Figure 6. Rotational diffusion coefficient, $D_{r}$, of perylene in each matrix against temperature: (O) uncured prepolymer mixture $1 ;(\boldsymbol{A})$ uncured prepolymer mixture 2; $(O)$ cured MQ 60; $(\square)$ cured MQ 100; $(\triangle)$ cured MQ 120; $\diamond)$ cured MQ 150; $(\times)$ PMMA.

$D_{\mathrm{r}}$ in the cured MQ resins are smaller than those in the uncured prepolymer mixtures at $300 \mathrm{~K}$ and show only a slight decrease with decreasing temperature. Therefore, $D_{\mathrm{r}}$ for perylene in the cured MQ resins becomes larger than in uncured prepolymer mixtures at low temperatures below $125 \mathrm{~K}$. These results would be explained as follows: Change in packing and the dense aggregation of the nanoparticles in the uncured prepolymer mixtures around perylene molecules and gradual restriction on thermal fluctuation of flexible siloxane chains with decreasing temperature prevent perylene from rotating freely in the range of nano-second lifetime of the excited state of perylene. The change in packing and the dense aggregation of the nanoparticles is a continuous phenomenon in the temperature range $90-300 \mathrm{~K}$, which causes the continuous rapid decrease in $D_{\mathrm{r}}$ for the uncured prepolymer mixtures with decreasing temperature. Hydrosilylation curing reactions link the nanoparticles, fix the spatial positions of nanoparticles, and prevent change in packing conformation and aggregation during cooling for the cured MQ resins. As a result, larger local space around perylene is retained even at $90 \mathrm{~K}$ in the cured MQ resins than in the uncured prepolymer mixtures.

In PMMA, $D_{\mathrm{r}}$ is much smaller than in the cured MQ resin system and is independent of temperature. Itagaki et al. discuss the fluorescence anisotropy ratio of anthracene and pyrene in PMMA at room temperature and at $77 \mathrm{~K} .{ }^{34}$ They report the same values at room temperature and $77 \mathrm{~K}$ for both chromophore cases. Our results of perylene in PMMA agree well with their study. That is, rotation of various organic dyes is considerably restricted even at room temperature in PMMA. The difference in $D_{\mathrm{r}}$ between the cured MQ resins and PMMA would be attributed to the effects of flexibility of the siloxane $\mathrm{Si}-\mathrm{O}-\mathrm{Si}$ chains.

\section{Comparison with the Results of Photoisomerization of Azobenzene}

We investigated the local free volume and thermal fluctuation in MQ resins using trans-to-cis photoisomerization of azobenzene in our previous study. ${ }^{10}$ The final cis fraction in the photoisomerization at $4 \mathrm{~K}$ cor- responds to the amount of the local site whose intrinsic size is larger than the critical size for photoisomerization of azobenzene. At higher temperatures than $4 \mathrm{~K}$ the effect of local relaxation of the matrix is added to the intrinsic size of the local site, which appears as fluctuation of size affecting the photoisomerization behavior of the doped dye. $^{35,36}$ The final cis fraction of azobenzene in the uncured prepolymer mixture was about $80 \%$ at $300 \mathrm{~K}$ to $20 \mathrm{~K}$. In the cured MQ resin the final cis fraction decreased gradually from $300 \mathrm{~K}$ to $20 \mathrm{~K}$. At $4 \mathrm{~K}$ the reverse was observed where the final cis fraction in the uncured prepolymer mixture markedly decreased to $10 \%$ which is smaller than $22 \%$ in cured MQ 120 .

In the present fluorescence study, change in the packing of nanoparticles in uncured prepolymer is proven to be continuous from $300 \mathrm{~K}$ to $90 \mathrm{~K}$ for the first time, which was not noted in our previous azobenzene study. The inversion of $D_{\mathrm{r}}$ between uncured prepolymer and cured MQ resins at $125 \mathrm{~K}$ in the fluorescence study corresponds to that of final cis fraction at $4 \mathrm{~K}$ in the photoisomerization of azobenzene. The suggestion that hydrosilylation curing reactions fix spatial position of the nanoparticles by linking them resulting in keeping larger local space around probe molecules at low temperatures holds for both the present fluorescence and previous photoisomerization results.

The excited-state lifetime of perylene is in the order of nanoseconds, while that of azobenzene, picoseconds in solution. ${ }^{37}$ Though the time for fluorescence depolarization of perylene is larger than that for photoisomerization of azobenzene, the inversion appears at $125 \mathrm{~K}$ in fluorescence study while at $4 \mathrm{~K}$ in the photoisomerization study. There are two possible explanation for this difference. The first is "accumulation effect in the case of photochemical reaction". Once transto-cis photoisomerization of azobenzene occurs, the generated cis-azobenzene accumulates during the experiments (an hour) because of redistribution in conformation of polymer chains and resulting generation of photoisomerizable sites with enough local size, ${ }^{35}$ while the result of rotation of perylene is not accumulated. The second is "difference in sweep volume". Sweep volume $^{38,39}$ is required van der Waals volume swept out by moving phenyl group in photoisomerization of azobenzene and rotating perylene molecules in fluorescence depolarization. The size of a local site where dye molecules exist affects the photoisomerization or fluorescence depolarization. This size includes intrinsic size and effects of thermal fluctuation arising from local relaxation of the chains within the lifetime of the excited state of the probe. The sweep volume for photoisomerization of azobenzene may be smaller than that for the rotation of perylene.

\section{CONCLUSION}

We investigated the local structure and dynamics of the MQ resin system from the results of the rotational diffusion coefficient, $D_{\mathrm{r}}$, of perylene, and compared them with the results of final cis fraction of trans-to-cis photoisomerization of azobenzene at various temperatures. In the uncured prepolymer, possibly an assembly of nanometer-scale particles, perylene rotates with the 
equivalent value of $D_{\mathrm{r}}$ to that in $\mathrm{C}_{16} \mathrm{H}_{34}$ at room temperature. The rapid decrease in $D_{\mathrm{r}}$ for the uncured prepolymer with decreasing temperature indicates that dense packing and aggregation of the prepolymer nanoparticles restrict the local mobility of perylene continuously from $300 \mathrm{~K}$ to $90 \mathrm{~K} . D_{\mathrm{r}}$ in the cured MQ resins is almost independent of temperature. Perylene rotates more easily in the cured MQ resin than uncured prepolymer at $90 \mathrm{~K}$ contrary to the case at room temperature. These results suggest that hydrosilylation cure reaction fixes the spatial position of nanoparticles and retains the local space around perylene even at low temperature.

Acknowledgments. This work was partly supported by the Grant-in-Aid for Scientific Research on Priority Areas, "New Polymers and Their Nano-Organized Systems"(No. 277/08246211), from the Ministry of Education, Science, Sports and Culture of Japan and funding from Dow Corning Asia.

\section{REFERENCES}

1. R. H. Baney, M. Itoh, A. Sakakibara, and T. Suzuki, Chem. Rev., 95, 1409 (1995)

2. W. G. Klemperer and S. D. Ramamurthi, J. Non-Cryst. Solids, 121, $16(1990)$

3. J. K. Bailey, C. W. Macosko, and M. L. Mecartney, J. Non-Cryst. Solids, 125, 208 (1990).

4. J. C. Pouxviel, J. P. Boilot, J. C. Beloeil, and J. Y. Lallemand, J. Non-Cryst. Solids, 89, 345 (1987).

5. J. C. Pouxviel and J. P. Boilot, J. Non-Cryst. Solids, 94, 374 (1987).

6. R. A. Assink and B. D. Kay, J. Non-Cryst. Solids, 99, 359 (1988).

7. L. V. Ng, P. Thompson, J. Sanchez, C. W. Macosko, and A. V. McCormick, Macromolecules, 28, 6471 (1995)

8. S. Kohjiya, Y. Takada, K. Urayama, Y. Tezuka, and A. Kidera, Bull. Chem. Soc. Jpn., 69, 565 (1996).

9. F. O. Stark, J. R. Falender, and A. P. Wright, in "Comprehensive Organometallic Chemistry," G. Wilkinson, F. G. A. Stone, and E. W. Abel, Ed., Pergamon Press, New York, N.Y., 1982, p 305.

10. K. Yoshii, T. Yamashita, S. Machida, K. Horie, M. Itoh, F. Nishida, and S. Morino, J. Non-Cryst. Solids, 246, 90 (1999).

11. H. L. Li, Y. Ujihira, T. Yoshino, K. Yoshii, T. Yamashita, and K. Horie, Polymer, 39, 4075 (1998).
12. H. Itagaki, K. Horie, and I. Mita, Prog. Polym. Sci., 15, 361 (1990).

13. F. Tsunomori and H. Ushiki, Polym. J., 28, 576 (1996).

14. F. Tsunomori, H. Ushiki, and K. Horie, Polym. J., 28, 582 (1996).

15. F. Tsunomori and H. Ushiki, Polym. J., 28, 588 (1996).

16. A. D. Stein, D. A. Hoffmann, A. H. Marcus, P. B. Leezenberg, C. W. Frank, and M. D. Fayer, J. Phys. Chem., 96, 5255(1992).

17. P. B. Leezenberg, A. H. Marcus, C. W. Frank, and M. D. Fayer, J. Phys. Chem., 100, 7646 (1996).

18. J. Horinaka, S. Amano, H. Funada, S. Ito, and M. Yamamoto, Macmomolecules, 31, 1197 (1998).

19. S. Tsuneda, T. Endo, K. Saito, K. Sugita, K. Horie, T. Yamashita, and T. Sugo, Chem. Phys. Lett., 275, 203 (1997).

20. M. Choi, D. Jin, H. Kim, T. J. Kang, S. C. Jeoung, and D. Kim, J. Phys. Chem. B, 101, 8092 (1997).

21. E. D. Niemeyer and F. V. Bright, Macromolecules, 31, 77 (1998).

22. N. C. Maiti, M. M. G. Krishna, P. J. Britto, and N. Periasamy, J. Phys. Chem. B, 101, 11051 (1997).

23. G. K. Hiller and R. V. Wandruszka, J. Colloid Interface Sci., 177, 156 (1996).

24. S. Grigoras, R. G. Schmidt, R. B. Taylor, L. Carpenter, and G. C. Ruben, XXVII Organosilicon Symposium, March 18-19, 1994.

25. A. Einstein, Ann. Phys., Ser. 4, 19, 371 (1906).

26. M. D. Barkley, A. A. Kowalczyk, and L. Brand, J. Chem. Phys., 75, 3581 (1981).

27. E. R. Pantke and H. Labhart, Chem. Phys. Lett., 23, 476 (1973).

28. J. R. Lakowicz, H. Cherek, and B. P. Maliwal, Biochemistry, 24, 376 (1985).

29. B. Brocklehurst and R. N. Young, J. Chem. Soc., Faraday Trans., 90, 271 (1994).

30. D. W. Piston, T. Bilash, and E. Gratton, J. Phys. Chem., 93, 3963 (1989).

31. H. Labhart and E. R. Pantke, Chem. Phys. Lett., 23, 482 (1973).

32. Y. Jiang and G. J. Blanchard, J. Phys. Chem., 98, 6436 (1994).

33. D. R. Lide, Ed., "CRC Handbook of Chemistry and Physics," 74th ed, CRC Press, Boca Raton, FL, 1993.

34. H. Itagaki, K. Horie, I. Mita, M. Washio, S. Tagawa, Y. Tabata, H. Sato, and Y. Tanaka, Macromolecules, 23, 1686 (1990).

35. I. Mita, K. Horie, and K. Hirao, Macromolecules, 22, 558 (1989).

36. T. Naito, K. Horie, and I. Mita, Polymer, 34, 4140 (1993).

37. I. K. Lednev, T.-Q. Ye, R. E. Hester, and J. N. Moore, J. Phys. Chem., 100, 13338 (1996).

38. J. G. Victor and J. M. Torkelson, Macromolecules, 20, 2241 (1987).

39. T. Naito, K. Horie, and I. Mita, Macromolecules, 24, 2907 (1991). 